\section{Exantemas en pediatría}

\section{RESUMEN}

Los exantemas de la infancia son erupciones cutáneas localizadas o generalizadas que pueden ser causados por virus, bacterias, medicamentos o estar asociados con enfermedades sistémicas. La mayoría de los exantemas en la infancia son diagnosticados y tratados por el médico de atención primaria y por el pediatra, por lo que es deseable que ambos estén familiarizados con los exantemas clásicos y los atípicos.

Palabras clave: exantemas, pediatría, erupciones, cutáneas.

\section{Exanthems in children}

\section{ABSTRACT}

Childhood exanthems are cutaneous eruptions localized or generalized that can be caused by virus, bacteria, drugs, or be associated to systemic diseases. Most exanthems are initially diagnosed and treated by pediatricians, therefore it's important that they know these diseases in both, classic and atypical forms.

Key words: exanthems, pediatric, eruptions, cutaneous.
Carolina Guadalupe Palacios-López ${ }^{1}$ Carola Durán-Mckinster ${ }^{2}$ Luz Orozco-Covarrubias ${ }^{1}$ Marimar Saéz-de-Ocariz ${ }^{1}$ María Teresa García-Romero ${ }^{1}$ Ramón Ruiz-Maldonado ${ }^{1}$

${ }^{1}$ Adscritos al Servicio de Dermatología.

2 Jefa del Servicio de Dermatología.

Instituto Nacional de Pediatría, Ciudad de México.
Recibido: 6 de marzo del 2015

Aceptado: 20 de mayo del 2015

Correspondencia: Dra. Carola Durán Mckinster Servicio de Dermatología Instituto Nacional de Pediatría Insurgentes Sur 3700- C CP 04530 México, D.F.

clindermaped@gmail.com

Este artículo debe citarse como

Palacios-López CG, Durán-Mckinster C, OrozcoCovarrubias L, Saéz-de-Ocariz M, García-Romero MT, Ruiz-Maldonado R. Exantemas en pediatría. Acta Pediatr Mex 2015;36:412-423. 


\section{INTRODUCCIÓN}

Los exantemas de la infancia son erupciones cutáneas localizadas o generalizadas que pueden ser causados por virus, bacterias, medicamentos o estar asociados con enfermedades sistémicas. No es correcto utilizar el anglicismo "rash" para referirse a los exantemas.

Al explorar a un niño con exantema debemos evaluar:

1. Morfología de las lesiones individuales

2. Patrón de distribución

3. Síntomas prodrómicos y concurrentes

4. Exposiciones conocidas

5. Enantema asociado (erupción en membranas mucosas)

6. Epidemiología local

7. Hallazgos de examen físico y aparatos y sistemas

Al final debemos tomar en cuenta todos los datos clínicos con el aspecto general del paciente.

Los exantemas pueden dividirse, de acuerdo con su morfología, en:

- Maculares o manchas: cambio de coloración de la piel, lesión plana

- Eritematosos: de color rojo

- Vesiculares: con vesículas (colecciones de líquido seroso hasta de $3 \mathrm{~mm}$ )

- Papulares: pápula, lesión sólida elevada en la superficie de menos de $1 \mathrm{~cm}$

- Pustulares: lesión elevada en la superficie con contenido purulento

- Petequiales: manchas purpúricas

También se denomina a los exantemas como:

- Morbiliforme: similar al sarampión (maculopapular)
- Rubeoliforme: similar a la rubeola

- Escarlatiniforme: similar a la escarlatina

- Urticarial: similar a la urticaria (roncha, lesión elemental de la urticaria consiste en una lesión sólida, mal definida y de distintos tamaños)

Con patrón:

- Anular: lesiones en forma de anillos

- Reticular: lesiones en forma reticulada o de encaje

La mayoría de los exantemas infantiles son causados por virus y en menor frecuencia por bacterias, aunque en ocasiones no se identifique al agente causal.

A principios del siglo $\mathrm{XX}$ fueron enumerados los exantemas infantiles clásicos, en sarampión, rubéola, varicela, enfermedad de Dukes-Fillatow (que ya no existe), eritema infeccioso y exantema súbito; dicha clasificación ya es obsoleta.

\section{EXANTEMAS INFECCIOSOS}

\section{Sarampión}

Causado por el virus del sarampión, un ARN virus (Paramyxoviridae). Tienen riesgo de contraerlo niños preescolares no vacunados y adolescentes en quienes falló la vacunación. Se presenta en invierno y primavera. El periodo de incubación es de 8 a 12 días. El pródromo se presenta de 7 a 11 días después de la exposición con fiebre, tos, coriza y conjuntivitis. El enantema es patognomónico, Ilamado manchas de Koplik, como pápulas puntiformes de color blanco-grisáceo y eritematosas distribuidas en la mucosa yugal. Sin embargo, rara vez se observa ya que aparece dos días antes del exantema y dura dos días después de su inicio. El exantema aparece en el día 14 después de su exposición y entre dos y cuatro días después del pródromo. 
Es cefalocaudal; se inicia en la cara y luego se disemina al tronco y a las extremidades. El exantema es morbiliforme con manchas y pápulas eritematosas que confluyen y desaparecen en el mismo orden que han aparecido. Dejan manchas de color café y descamación. ${ }^{1}$

\section{Sarampión modificado}

Aparece en un individuo previamente vacunado. El pródromo es más leve y con duración menor; el exantema es menos notable. En ocasiones no aparecen las manchas de Koplik. Es difícil hacer su diagnóstico. ${ }^{1}$

\section{Sarampión atípico}

Raro en personas con exposición al virus del sarampión después de vacunarse con la vacuna de virus muertos del sarampión utilizada en Estados Unidos en los años 60 del siglo pasado por corto tiempo. Se presenta con fiebre alta, cefaleas y mialgias, exantema, neumonía. Puede haber manifestaciones hemorrágicas. El diagnóstico del sarampión es clínico; en ocasiones es necesario confirmarlo con estudios serológicos que muestran un aumento cuatro veces mayor del valor.

\section{Tratamiento}

Sintomático en casos sin complicaciones. No existe un antiviral específico. La Organización Mundial de la Salud ha recomendado complementos de vitamina A para los niños con sarampión que residen en zonas con carencias de la misma o donde la letalidad del sarampión sea $1 \%$ o mayor. ${ }^{1}$

Los niños hospitalizados con sarampión deben permanecer en aislamiento respiratorio por cuatro días a partir de la aparición del exantema. La mayoría de los pacientes se recupera sin secuelas y tendrá una protección inmunitaria frente a reinfección durante toda la vida.

\section{Complicaciones}

Otitis media, bronconeumonía, encefalitis, miocarditis, pericarditis y panencefalitis esclerosante subaguda, que es una enfermedad neurodegenerativa retardada caracterizada por crisis epilépticas, cambios de la personalidad, coma y en ocasiones la muerte. Ocurre en $1 \mathrm{de}$ cada 100000 pacientes con sarampión. ${ }^{1}$

\section{Fiebre escarlatina}

Es debida a la toxina eritrógena del estreptococo betahemolítico del grupo A. Se observa en niños de 1 a 10 años de edad y se transmite a través de secreciones respiratorias. Inicia con fiebre, cefalea y amigdalitis. Eritema oroamigdalino, exudados y petequias en el paladar, los primeros días se observa lengua blanca y al cuarto día se observa la lengua roja brillante (en fresa) Figura 1. El exantema es maculopapular, eritematoso, se describe como "papel de lija". Afecta el tronco y las extremidades y puede acentuarse en zonas de pliegues en antebrazos, donde se observan petequias (líneas de Pastia). El exantema desaparece en cuatro o cinco días con descamación severa de manos y pies. Las complicaciones de la escarlatina son neumonía, pericarditis, meningitis, hepatitis, glomerulonefritis y fiebre reumática. El tratamiento con penicilina debe iniciarse antes de nueve días de la aparición de los síntomas faríngeos. En caso de alergia a la penicilina se dará eritromicina.

\section{Rubéola}

Tiene una distribución mundial. Es producida por un ARN virus de la familia Togaviridae. La infección posnatal se contagia mediante contacto directo o por gotas de las secreciones nasofaríngeas. Hasta 50\% de los casos de rubéola son asintomáticos y es frecuente la enfermedad leve con remisión espontánea. El periodo de incubación es de 14 a 23 días. El pródromo se presenta de dos a cinco días antes 


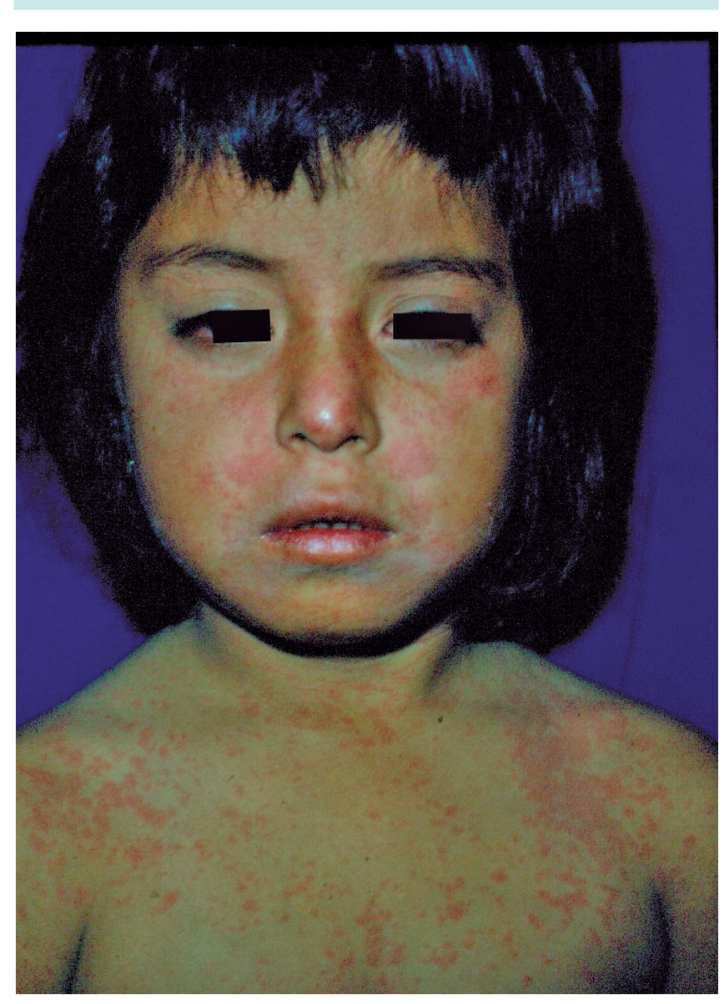

Figura 1. Sarampión: exantema maculopapular eritematoso.

de que aparezca el exantema, éste es maculopapular eritematosos y rosado, afecta más la cara y el tronco; es cefalocaudal. Remite en tres días en el mismo orden en que apareció (Figura 2). Existe linfadenopatía generalizada, sobre todo en la región suboccipital, posauricular y cervical. Son frecuentes las artralgias ${ }^{1}$.

Enantema de Forschheimer. Se manifiesta con máculas eritematosas y petequias en el paladar blando.

El diagnóstico es clínico pero se apoya con las pruebas serológicas. El anticuerpo IgM específico de la rubéola indica una infección reciente.

El tratamiento es sintomático; los pacientes hospitalizados tienen que ser aislados y los niños no

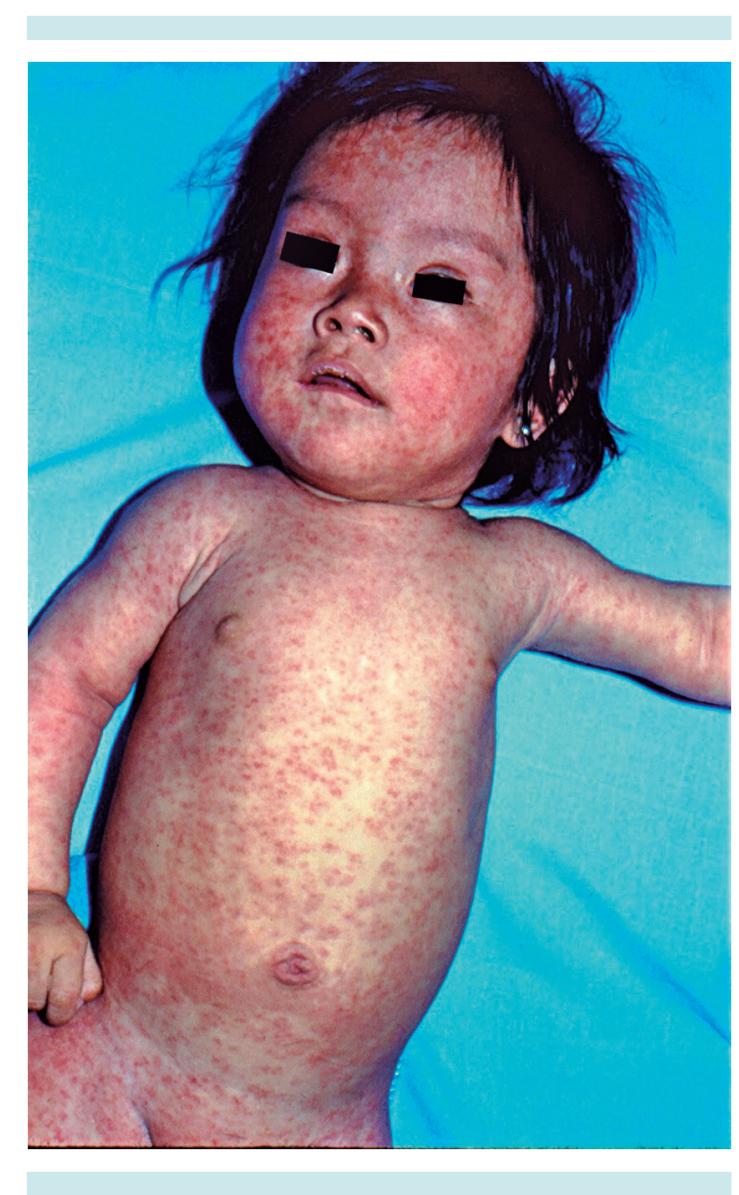

Figura 2. Rubéola: erupción maculopapular eritematosa.

deben salir de casa los siete días siguientes a la aparición del exantema ${ }^{1}$.

\section{Eritema infeccioso}

Es la quinta enfermedad provocada por el parvovirus B19. Es más frecuente en niños en edad escolar. Se transmite por vía respiratoria. Se trata de una viremia que termina a los siete días con la producción de anticuerpo IgM anti-B19. Se inicia con pródromo con fiebre y cefalea. El anticuerpo IgG aparece durante la tercera semana de la enfermedad y coincide con la aparición de exantema y artralgias, así que los pacientes 
con exantema no se consideran infecciosos. El exantema inicia con el enrojecimiento de mejillas característico (signo de la bofetada); aparece a los dos o tres días de los síntomas prodrómicos. En la segunda fase aparece un exantema reticulado "como encaje" sobre el tronco y las extremidades; puede haber prurito (Figura 3). El exantema desaparece y vuelve a aparecer ante un estímulo como la luz solar, con temperatura ambiental alta y a la actividad física. Dura hasta tres semanas más. ${ }^{1,2}$ Los síntomas articulares aparecen en 8 a 10\% de los casos; son transitorios y remiten espontáneamente. El virus B19 tiene una gran afinidad con los precursores eritroides; puede ocasionar anemia transitoria o crisis aplásica transitoria. Debido a que el B19 puede cruzar la placenta es factible la infección fetal en mujeres no inmunizadas con infección aguda; puede causar abortos y muerte fetal. El eritema infeccioso es muy común en niños; es típicamente agudo y se alivia espontáneamente; sin embargo, en algunos casos se ha señalado que puede desencadenar enfermedades autoinmunitarias y causar exacerbación de enfermedades preexistentes, aunque el papel exacto de la asociación del virus B19 con enfermedades reumáticas todavía está por definirse.

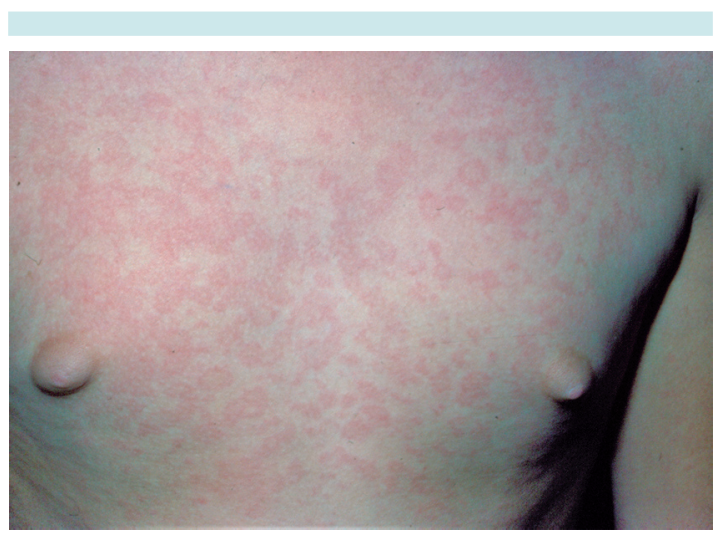

Figura 3. Eritema infeccioso maculopopular en encaje.
Síndrome papulopurpúrico en guante y calcetín

Es causado frecuentemente por parvovirus B19. Es más común en adolescentes y en adultos jóvenes; en primavera y verano. Es muy pruriginoso. Puede acompañarse de enantema purpúrico en paladar duro y blando, faringe y lengua. Aparece súbitamente inflamación simétrica, marcado eritema, pápulas y lesiones purpúricas en manos y pies. Se acompaña de fiebre, artralgias, malestar general, problemas respiratorios y gastrointestinales. Rara vez se observan leucopenia y trombocitopenia. Remite espontáneamente en dos semanas y casi nunca recidiva. En niños inmunocompetentes el tratamiento es sintomático. En mujeres embarazadas expuestas al virus B19 es necesario realizar serología buscando anticuerpos IgM e IgG anti-B19. Si se confirma la infección aguda está indicada la ecografía fetal seriada. ${ }^{1,2}$

\section{Exantema súbito o roséola infantil}

Es causado por los virus del herpes humano tipos 6 o 7 . Más de $95 \%$ se observa en menores de 3 años. Los virus del herpes humano 6 y 7 son miembros ubicuos de la familia Herpesviridae. Estos virus $A D N$ infectan preferentemente a células $T$ activadas, lo que causa un aumento de la actividad de los linfocitos citolíticos naturales y la inducción de numerosas citocinas. Tal como sucede con otros herpesvirus se vuelve latente después de la infección primaria y puede reactivarse durante los periodos de inmunidad alterada. Los estudios serológicos han demostrado que la mayoría de los niños han sido infectados con virus del herpes humano antes de los 3 años de edad y con el tipo 7 entre los 6 y los 10 años. Se piensa que la transmisión de los tipos 6 y 7 ocurre por medio de la saliva. Se ha confirmado la transmisión horizontal entre madre e hijo. Aunque la mayoría de los recién nacidos posee anticuerpos adquiridos a través de la placenta a los 6 meses casi todos son seronegativos y por 
lo tanto sensibles a la infección. El tipo 6 se ha dividido en las variantes A y B. La mayoría de las infecciones infantiles pertenecen a la variante virus del herpes humano $6 \mathrm{~B}$ y afecta con mayor frecuencia a pacientes inmunodeprimidos.

El exantema súbito se presenta generalmente con fiebre de tres días $\left(38.3-41^{\circ} \mathrm{C}\right)$. Se incuba por un periodo de 5 a 15 días. Cuando desaparece la fiebre aparece el exantema que se inicia en el tronco, luego se extiende hasta las extremidades, cuello y cara. Se observan máculas y pápulas con eritema. El exantema desparece en tres días (Figura 4). En dos tercios de los pacientes puede observarse enantema conocido como manchas

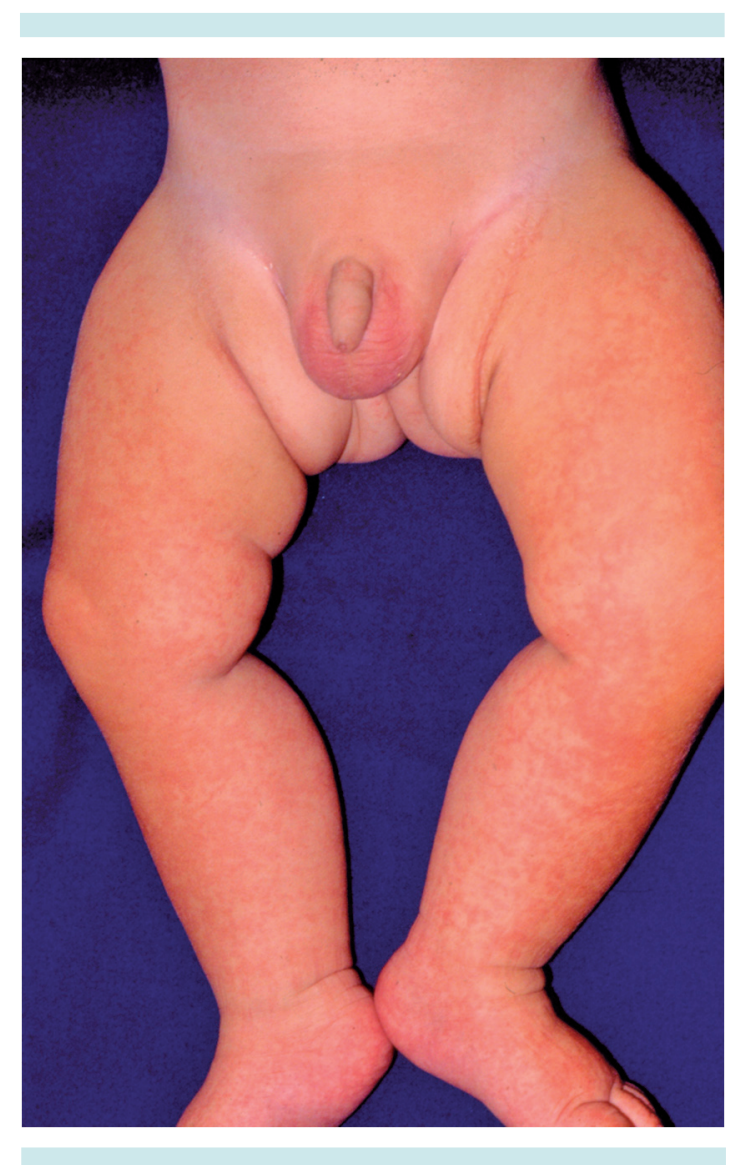

Figura 4. Exantema súbito: erupción con pequeñas pápulas y eritema. de Nagayama, manchas eritematosas en la mucosa del paladar blando y la úvula.

La infección primaria con virus del herpes humano 6 también puede ser asintomática o puede aparecer de manera distinta a la del exantema súbito clásico. Una fiebre inespecífica en niños con o sin otitis media puede deberse a infección con virus del herpes humano 6. Las convulsiones febriles en niños pequeños también pueden deberse a esta infección primaria. Otras complicaciones posibles son del sistema nervioso central e incluyen encefalopatía y encefalitis, que suelen aparecer durante la fase anterior al exantema y que pueden ser causa de morbilidad neurológica a largo plazo. La encefalitis debida a virus del herpes humano 6 se ha observado tanto en pacientes inmunocompetentes como inmunodeprimidos. Los receptores de trasplantes de órganos sólidos o de médula ósea tienen mayor riesgo de activación de la enfermedad, que puede ser asintomática o presentarse con exantema, fiebre, encefalitis, neumonitis, hepatitis o insuficiencia de la médula ósea. En algunos pacientes la presentación clínica de la reactivación del virus del herpes humano 6 puede ocultar la de una enfermedad injerto contra huésped aguda. No es necesario realizar un tratamiento del exantema súbito ya que la enfermedad suele remitir espontáneamente sin secuelas a largo plazo. Sin embargo, son necesarios más estudios para identificar las opciones de tratamiento eficaces debido al gran número de complicaciones que pueden asociarse con una infección grave o en un paciente inmunodeprimido.

\section{Varicela}

Es producida por el virus de la varicela y del herpes zóster, miembro de la familia Herpesviridae. Es causante primero de varicela y en un segundo brote de herpes zóster. Se encuentra en todo el mundo y se presenta más frecuentemente en invierno y primavera. La varicela es 
una enfermedad muy contagiosa, más aún entre pródromos y los primeros días de la infección cutánea. Su periodo de incubación es muy largo (de 14 a 21 días). La varicela comienza con pródromo de fiebre, cefalea, malestar general, artralgias y mialgias. Entre 24 y 48 horas después aparecen máculas o pápulas con eritema que progresan rápidamente a vesículas. Comienza en la piel cabelluda, la cara o el tronco y después en las extremidades. Las lesiones antiguas forman costras y la aparición de nuevas lesiones hace que se vean en fases diferentes. Se requiere diagnóstico diferencial con prurigo por insectos que a menudo se confunde con varicela (Figura 5). Las lesiones de la varicela dejan cicatrices

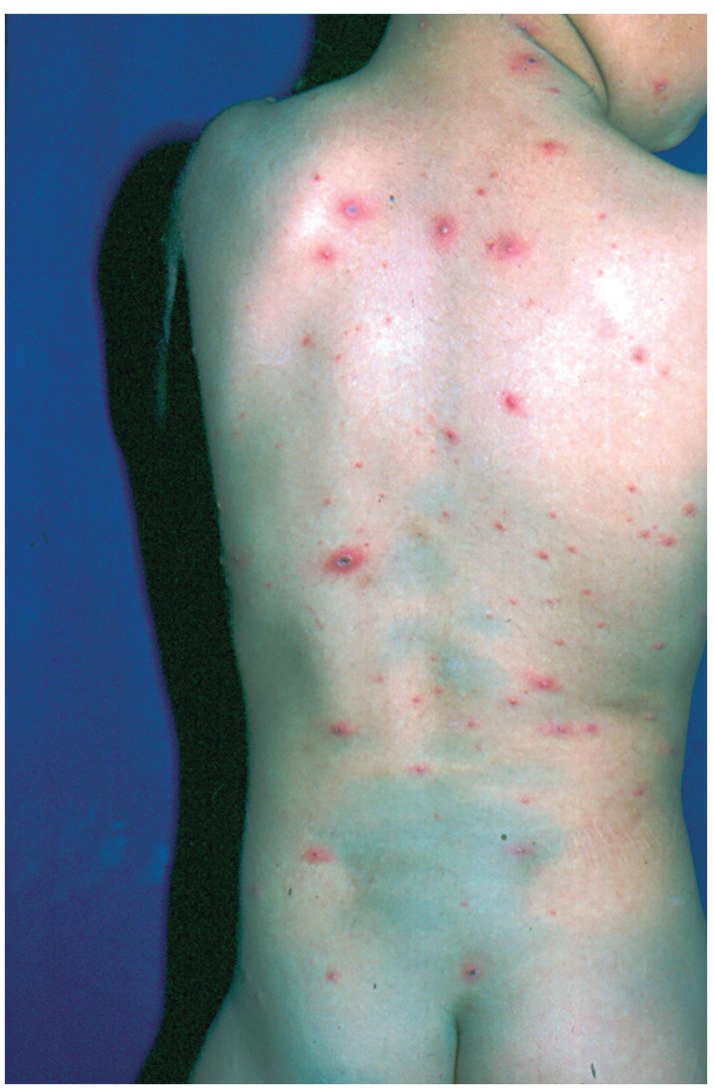

Figura 5. Varicela: vesículas, pápulas y costras con eritema alrededor. deprimidas, hiper- o hipopigmentadas. También se puede observar un enantema con erosiones dolorosas en orofaringe, conjuntivas o mucosas vaginales. Se transmite por las gotitas de saliva; el virus llega a los ganglios linfáticos regionales y después se origina la viremia con diseminación. La exposición al sol o la presencia de dermatitis como la atopia pueden agravar la erupción de la varicela. La infección primaria causa una respuesta inmunitaria humoral con producción de anticuerpos $\lg \mathrm{A}$, IgM, e $\lg \mathrm{G}$ antivirus de la varicela y del herpes zóster, estos últimos dan protección ante una reinfección. Los pacientes se consideran infecciosos hasta que todas las lesiones se hayan secado y haya aparecido la costra.

La varicela remite espontáneamente en la mayoría de los pacientes inmunocompetentes. La complicación más frecuente es la sobreinfección bacteriana secundaria que se debe a Staphylococcus aureus o a estreptococo betahemolítico del grupo A. Puede haber celulitis, abscesos subcutáneos y linfadenitis regional. Los pacientes que desarrollan infección bacteriana secundaria pueden complicarse con bacteriemia, neumonía, artritis u osteomielitis. Después de la infección bacteriana la afectación neurológica le sigue en frecuencia: encefalitis, meningoencefalitis, ataxia cerebelosa, mielitis transversa o síndrome de Guillain-Barré. La púrpura fulminante es una complicación rara y potencialmente mortal. Por supuesto, las complicaciones son más frecuentes y más severas en pacientes con inmunodepresión. El virus de la varicela y del herpes zóster se establece en los ganglios basales sensitivos de forma latente $y$, cuando existen condiciones en el huésped como inmunodepresión, estrés o exposición intensa al sol, puede reactivarse en una distribución dermatológica causando herpes zóster ${ }^{1}$.

El diagnóstico de la varicela es clínico pero cuando se tiene duda una prueba rápida es la 
de Tzanck que consiste en levantar la piel de la vesícula y realizar un raspado de la base de la misma. Cuando se trata de varicela se observan células gigantes multinucleadas y se puede iniciar el tratamiento. No es específica para el virus de la varicela y del herpes zóster. El tratamiento de la varicela en niños sanos es sintomático. La decisión de un tratamiento antiviral oral para la varicela depende del estado inmunológico, del paciente, de la extensión de la infección y del momento en que se ha establecido el diagnóstico. Debería tomarse en cuenta el tratamiento antiviral en personas con riesgo a tener varicela de moderada a grave, esto es: en mayores de 12 años, en los que padecen enfermedad cutánea o pulmonar crónicas y en los que reciben tratamiento crónico con salicilatos o corticoesteroides. En individuos sensibles con exposición conocida al virus las opciones incluyen la aplicación de gammaglobulina para varicela zóster o la vacuna de la varicela. La gammaglobulina para varicela zóster es una preparación con valores altos de inmunoglobulina (IgG) que se administra vía intramuscular. Se debería administrar antes de las 48 horas de la exposición, pero puede administrarse hasta 96 horas después.

Tipos de exposición al virus de la varicela y del herpes zóster:

- Vivir en la misma casa que un paciente infectado.

- Jugar con un paciente cara a cara en lugares cerrados.

- En el hospital: compañero de habitación con varicela, contacto cara a cara con personal o pacientes infectados, visitante infectado, contacto íntimo con una persona con zóster.

- En un recién nacido: aparición de varicela en la madre entre cinco días antes del parto o dos días después. ${ }^{1}$
Candidatos a gammaglobulina para varicela zóster:

- Niño inmunodeprimido.

- Mujer embarazada sensible.

- Recién nacido cuya madre desarrolla varicela.

- Prematuro hospitalizado.

\section{Exantema laterotorácico unilateral (exantema} periflexural asimétrico de la infancia)

No se ha confirmado aún su causa. Se han aislado adenovirus y un virus paragripal; también se aisló en otro estudio Spiroplasma sin que se haya confirmado en estudios posteriores. Se presenta entre el primero y los 5 años de edad, aparece en el tronco y se extiende hacia la axila; menos frecuentemente a la región inguinal o a una extremidad. Las lesiones cutáneas pueden ser máculas, pápulas escarlatiniformes, con patrón reticulado (Figura 6). Debido a su unilateralidad puede confundirse con una dermatitis por contacto. Existe pródromo con febrícula y síntomas respiratorios y gastrointestinales, cansancio y conjuntivitis; puede haber adenomegalias. Las lesiones pueden desaparecer en cuatro a ocho semanas. El tratamiento es sintomático. ${ }^{1}$

Acrodermatitis papular de la infancia (síndrome de Gianotti-Crosti)

La acrodermatitis papular de la infancia es un exantema producido por virus. Puede aparecer después de una infección por el virus de la hepatitis B. Es poco frecuente en Estados Unidos. Se observa en niños de entre uno y seis años de edad; tiene pródromo con fiebre, linfadenopatía y síntomas de las vías respiratorias superiores. El exantema es de papulovesículas monomórficas, eritematosas y edematosas distribuidas de manera simétrica sobre la cara y las superficies extensoras de las extremidades superiores e 


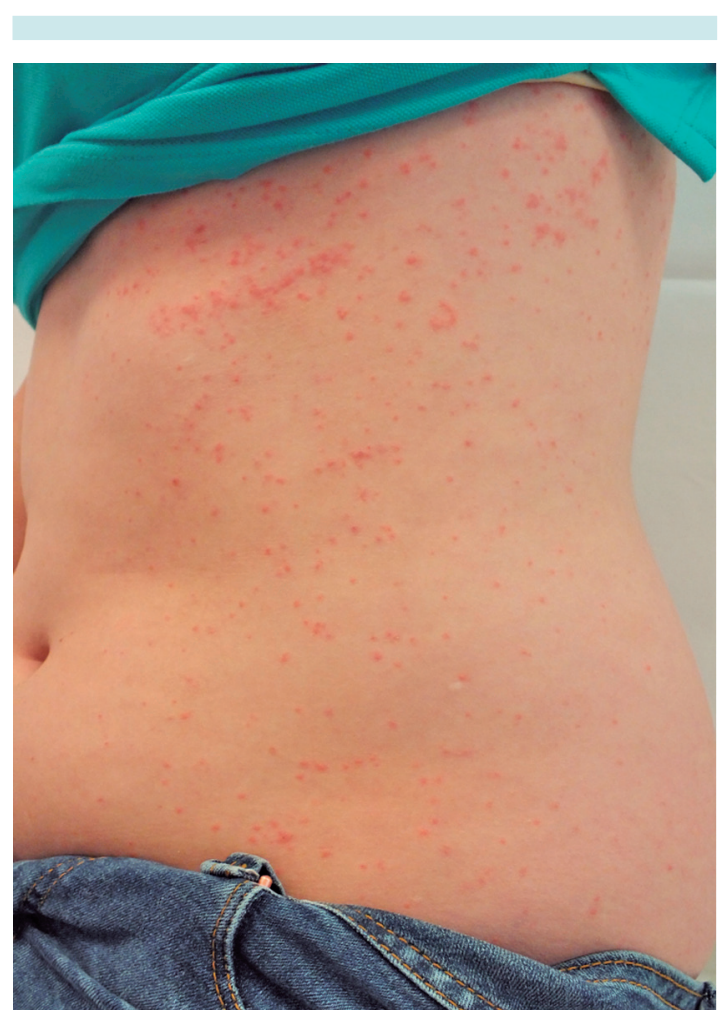

Figura 6. Exantema laterotorácico: pápulas eritematosas que confluyen en el tronco.

inferiores (Figura 7). Ocasionalmente afecta los glúteos y generalmente respeta al tronco. Puede observarse púrpura localizada. En la mayoría de los pacientes es asintomática. El tratamiento es sintomático. ${ }^{1}$

\section{Exantemas enterovíricos}

Los enterovirus son un grupo de los picornavirus. Pueden causar varios síndromes clínicos con exantema. Los enterovirus humanos son pequeños virus $A R N$ que incluyen ecovirus (31 serotipos), enterovirus 68-71 (4 tipos) y virus de la poliomielitis (tres tipos). La mayoría de las infecciones por enterovirus son benignas y se manifiestan con fiebre o con diferentes síntomas entre los que se encuentran: exantema viral de manos, pies y boca; herpangina, conjuntivitis

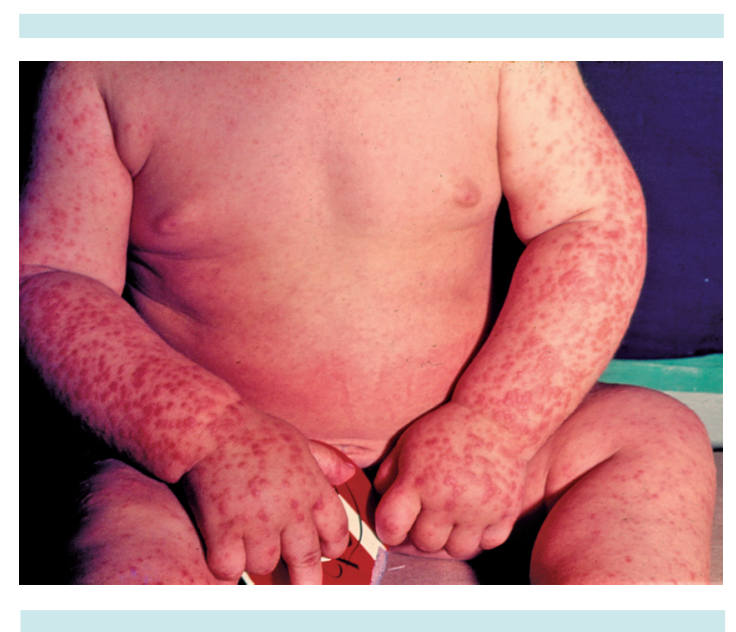

Figura 7. Síndrome Gianotti-Crosti con múltiples pápulas eritematosas, simétricas, en superficies extensoras de las extremidades.

hemorrágica y pleurodinia. Sin embargo, algunas infecciones graves o potencialmente mortales pueden deberse también a infección enteroviral como meningitis, encefalitis, miocarditis, septicemia neonatal y poliomielitis. El contagio con enterovirus se produce de persona a persona, por vía fecal u oral y en ocasiones por exposición frecuente al virus. Son habituales los exantemas inespecíficos debido a los enterovirus no poliomielíticos y pueden presentarse como erupciones maculares y papulares no pruriginosas con o sin petequias. Entre otros patrones de exantema pueden encontrase los urticariformes, escarlatiniformes, zosteriformes y vesiculares.

\section{Exantema de manos, pies y boca}

Afecta a niños entre uno y cuatro años de edad. Se le ha relacionado con enterovirus no poliomielíticos, Coxsackie A5, A7, A9, A10, A16 (el más frecuente), B1, B2, B3, y B5 y el enterovirus 71. ${ }^{1}$ El pródromo incluye fiebre y malestar general; el exantema característico es con vesículas de forma ovalada en manos, pies y boca. Puede aparecer una erupción maculopapular eritematosa y extenderse a glúteos y muslos (Figura 8). A 


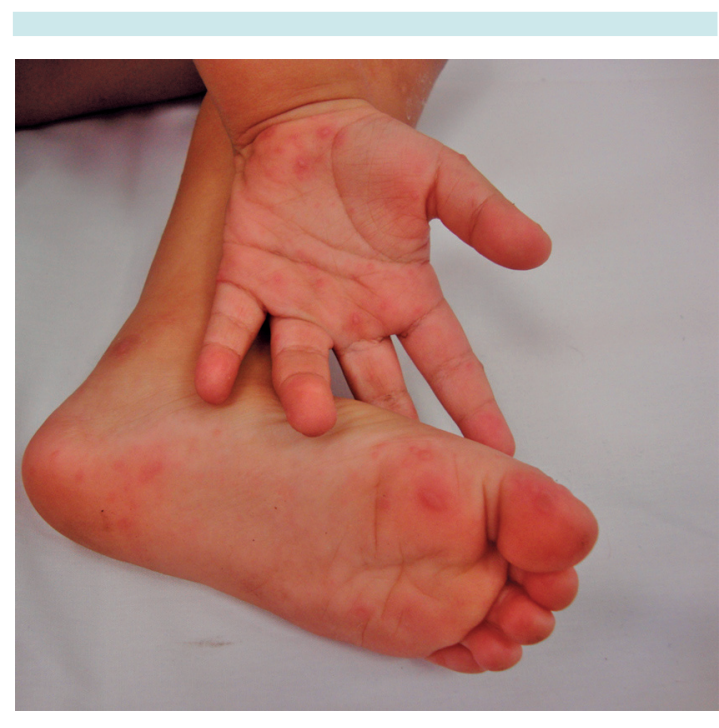

Figura 8. Mano, pie. Nótense las vesículas con fondo eritematoso.

la exploración física se encuentran adenopatías cervicales y submandibulares. El tratamiento es sintomático. Las epidemias de enterovirus 71 se han observado con mayor frecuencia asociadas con enfermedad grave y en niños menores de cinco años. La mayoría de las muertes se debe a edema o a hemorragia pulmonares. Otras complicaciones incluyen encefalitis, meningitis aséptica, parálisis flácida aguda y miocarditis. ${ }^{1}$

\section{Exantemas medicamentosos}

Las erupciones por fármaco más frecuentes son maculopapulares muy eritematosas. Casi siempre el exantema comienza de 7 a 14 días después de iniciado el medicamento y en ocasiones después de suspenderlo. Frecuentemente el exantema es simétrico y comienza en el tronco; las palmas y plantas suelen estar afectadas; puede haber algo de prurito y febrícula. La erupción se transforma en coloración marrón rojiza en 7-14 días y se descama. Los exantemas virales son indistinguibles de los exantemas causados por fármacos y se observan con mayor frecuencia en pacientes pediátricos. La eosinofilia es una de las reacciones a fármacos. Las reacciones a fármacos más graves son precedidas por edema facial o por una marcada eosinofilia, como ocurre en el síndrome de hipersensibilidad a fármacos (DRESS). El tratamiento es fundamentalmente de soporte. La decisión de suspender el fármaco se adopta en función de la necesidad de continuar con el medicamento. En algunos pacientes el exantema puede ser tolerable con el uso antihistamínicos y en otros progresa a eritrodermia; es decir, enrojecimiento de más de $80 \%$ de la piel. ${ }^{1}$

\section{Reacción con eosinofilia a fármacos y síntomas sistémicos}

La reacción exantematosa es más frecuente a alopurinol, fenitoína y dapsona. Se acompaña de fiebre y afectación a algunos órganos. Los pacientes que la padecen tienen una mortalidad de $10 \%$. Las manifestaciones clínicas comienzan de dos a seis semanas después de iniciado el medicamento responsable. La erupción cutánea se presenta en $75 \%$ de los casos. Suele comenzar en la cara con edema, especialmente periorbitario, seguido de eritema y prurito. El eritema se extiende caudalmente al resto del cuerpo, algunos pacientes progresan a síndrome de Stevens-Johnson o a una necrólisis epidérmica tóxica. El hígado es el órgano más afectado (80\%) con hepatitis a veces fulminante fatal. El riñón se afecta en $40 \%$ de los casos y el pulmón en $33 \%$. La pancitopenia es un dato de laboratorio de mal pronóstico. El diagnóstico temprano y la suspensión del medicamento son esenciales. ${ }^{3}$

\section{Exantemas asociados con enfermedades sistémicas}

\section{Enfermedad de Kawasaki}

La enfermedad de Kawasaki (síndrome ganglionar mucocutáneo agudo febril) es una 
enfermedad de la infancia que se ha convertido en una de las principales causas mundiales de cardiopatía adquirida. Tiene su máxima prevalencia en Japón y su incidencia es mucho mayor en las poblaciones asiático-americanas, lo cual sugiere una susceptibilidad genética. ${ }^{1-4}$ Es una vasculitis que afecta las arterias de pequeño y mediano calibre debido a un proceso inflamatorio agudo y autolimitado. La mayoría de los casos se presenta en niños menores de 5 años de edad pero existen casos descritos en etapa neonatal y en adolescentes. Debe considerarse el diagnóstico en un lactante con fiebre abrupta mayor de $39^{\circ} \mathrm{C}$, prolongada e inexplicable; puede persistir hasta cuatro semanas con ojos rojos más afectación de la conjuntiva bulbar y exantema. Los labios se ven rojos, secos, con fisuras y costrosos. Existe hiperemia de la mucosa oral y la lengua tiene aspecto de fresa. Hay edema en manos y pies, con eritema palmoplantar. Se produce descamación periungueal de presentación tardía y adenopatía cervical. El diagnóstico y el inicio del tratamiento suelen ocurrir más frecuentemente en los niños mayores. El exantema es polimorfo, puede ser maculopapular y escarlatiniforme pero, sobre todo el eritema y la descamación son característicos a nivel inguinal. Figuras 9 y 10. Existen eritema, induración y ulceración en el sitio de la vacunación de BCG. La biopsia de piel es inespecífica, aunque se observa vasculitis. Puede existir piuria estéril y velocidad de sedimentación globular aumentada. Otros datos de laboratorio son: leucocitosis, anemia normocítica, normocrómica, trombocitopenia en los casos con patología coronaria severa, trombocitosis en la fase subaguda, hipoalbuminemia, transaminasas aumentadas en el líquido cefalorraquídeo, pleocitosis mononuclear.

Las secuelas cardíacas son las complicaciones más graves de la enfermedad de Kawasaki. Las manifestaciones iniciales son derrame pericárdico y miocarditis; la más grave es la dilatación de las arterias coronarias que se produce hasta en $10 \%$ de los pacientes a pesar de un tratamiento

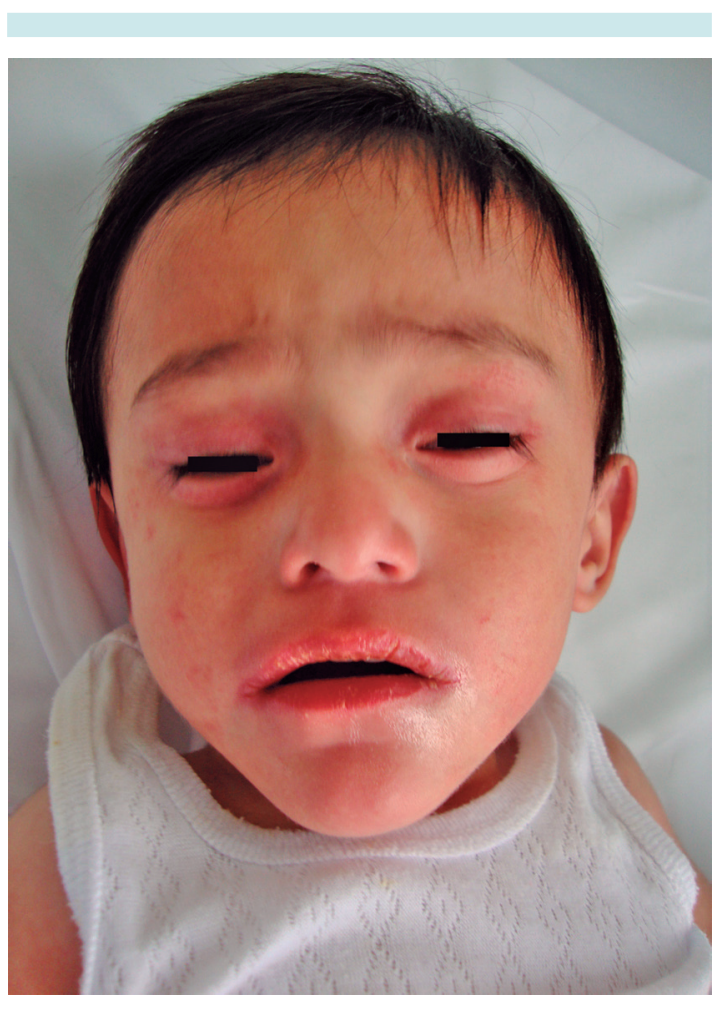

Figura 9. Kawasaki: eritema en párpados, labios eritematosos con descamación y fisuras.

adecuado. La etiología de la enfermedad de Kawasaki sigue sin conocerse a ciencia cierta. Se piensa que puede ser viral por la manera de presentarse con fiebre y exantema autolimitado. En recién nacidos y lactantes es rara, una explicación es que existe protección por el paso de anticuerpos maternos que confieren inmunidad. ${ }^{1-4}$ El manejo se apoya en la rapidez del diagnóstico y el tratamiento óptimo sigue siendo la inmunoglobulina intravenosa y la aspirina. ${ }^{5-6}$

\section{Kawasaki incompleta o atípica}

El diagnóstico de la enfermedad de Kawasaki se basa en cinco días con fiebre y más de cuatro de cinco criterios clínicos: inyección conjuntival sin exudado, linfadenopatía cervical, eritema en palmas y plantas con descamación periungueal, 


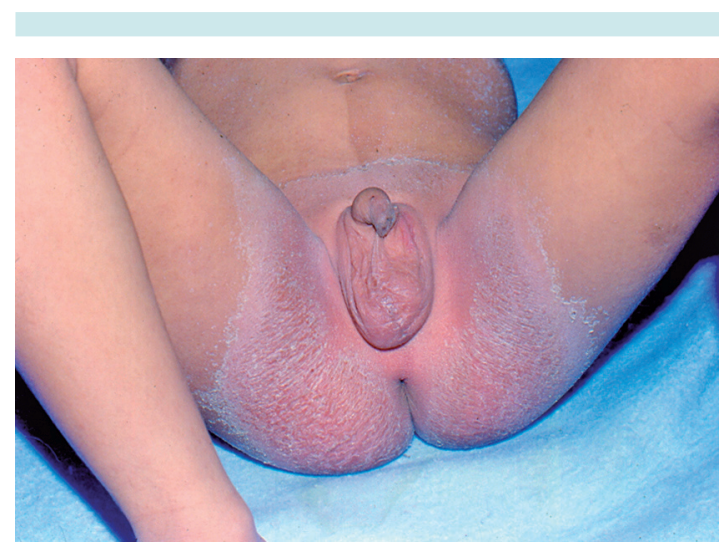

Figura 10. Kawasaki: región perineal con descamación severa.

alteraciones en la mucosa oral y exantema polimorfo. Los pacientes que no cumplen con estos criterios clásicos se catalogan como con enfermedad de Kawasaki incompleta. La denominación de enfermedad de Kawasaki atípica se reserva a los pacientes con alteraciones que generalmente no se observan en la enfermedad de Kawasaki como la insuficiencia renal. ${ }^{7}$

\section{REFERENCIAS}

1. Paller AS, Mancini AJ. Enfermedades Exantemáticas de infancia. En: Hurwitz Dermatología Pediátrica. Capítulo 16. Madrid: Marbán, 2014; pp. 681-721.

2. Reed MR, Gilliam BE, Syed RH, Moore TL. Rheumatic manifestations of parvovirus B19 in children. J Pediatr Infectious Diseases 4 2009:333-342 DOI 10.3233/JPI-2009-0195

3. Yi-Chun $\mathrm{Ch}$, Hisen-Ching $\mathrm{Ch}$, Chia-Yu Ch. Drug Reaction with Eosinophilia and Systemic Symptoms. Arch Dermatol 2010;146(12):1378.

4. Paller AS, Mancini AJ. Enfermedad de Kawasaki. En: Hurwitz Dermatología Pediátrica. Capítulo 16. Madrid: Marbán, 2014; pp. 918-927.

5. Saundel PR. Kawasaki disease. En: Cassidy J., Petty R, Laxer R. Lindsley C. Textbook of Pediatric Rheumatology. Philadelphia: Elsevier Saunders; 2005, pp. 521-538.

6. Bou R. Enfermedad de Kawasaki. Protoc diagn ter pediatr 2014;1:117-29.

7. Parra-Moronatti P, Rivera-Rodríguez L, Yamasaki-Nakashimada MA, Nava García F, Rodríguez-Álvarez J, BolañosReyes R. Enfermedad de Kawasaki refractaria, incompleta y atípica. Informe de un caso y revisión de la bibliografía. Arch Cardiol Mex 2011;81(3):221-227. 